\title{
EFFICACY OF BACLOFEN IN COMBINATION WITH INTENSIVE REHABILITATION IN SPASTIC CEREBRAL PALSY- A RANDOMIZED CLINICAL TRIAL
}

\author{
AMIN MR ${ }^{1}$, SAHA NC ${ }^{2}$, RAHMAN $^{3}$, HOSSAIN MS $^{4}$, ISLAM MJ ${ }^{5}$, ISLAM MS $^{6}$, HALDER D $^{7}$
}

\begin{abstract}
:
Objective: To find out the combined efficacy of baclofen and intensive rehabilitation in the treatment of spastic cerebral palsy.

Methods: This randomized clinical trial was conducted over 60 patients in Dhaka Medical College Hospital, Dhaka, between January and December 2011. The patient satisfying the inclusion and exclusion criteria was randomly enrolled into two groups; Group A (case) included 30 patients received only intensive rehabilitation and Group $B$ (control) included 30 patients who received baclofen orally two times daily according to the body weight regularly in combination with intensive rehabilitation 1 hour daily five times a week for 24 weeks. All patients were followed up at 4 weeks interval and were evaluated for a total of 24 weeks.

Results: Combination of baclofen and intensive rehabilitation has superior efficacy in reducing tone in spastic cerebral palsy over only rehabilitation measured by using Modified Ashworth scale $(p<0.001)$. Combination of baclofen and intensive rehabilitation is also superior in physician rating scale crouch $(p<0.0001)$ and foot contact, $(p<0.0001)$ and also improvement in gross motor function $(p<0.01)$.

Conclusion: Combination of baclofen and intensive rehabilitation group has superior efficacy than only rehabilitation group for reduction of generalized spasticity regarding muscle tone, range of motion of the joint and improvement of gait in cerebral palsy patients.
\end{abstract}

Key words: Spastic cerebral palsy, baclofen, rehabilitation.

J Dhaka Med Coll. 2014; 23(1) : 18-23.

\section{Introduction}

Cerebral Palsy (CP) describes a group of permanent disorders of the development of movement and posture, causing activity limitations that are attributed to nonprogressive disturbances that occurred in the developing fetal or infant brain. The motor disorders of cerebral palsy are often accompanied by disturbances of sensation, perception, cognition, communication, and behavior; by epilepsy, and by secondary musculoskeletal problems ${ }^{1}$. In a majority of cases, the predominant motor abnormality is spasticity $^{2}$. Cerebral palsy is the most common childhood disability with a prevalence of 1.5 to 3 per 1000 live births ${ }^{3,4}$. However, in a study at Physical Medicine \& Rehabilitation Department of BSMMU $1.72 \%$ patients were

1. Dr. Md. Ruhul Amin, Assistant Professor, Department of Physical Medicine \& Rehabilitation, Dhaka Medical College, Dhaka.

2. Dr. Narayan Chandra Saha, Associate Professor, Department of Pediatrics, National Institute of Neurosciences (NINS), Dhaka.

3. Prof. Sohely Rahman, Professor \& Head, Department of Physical Medicine \& Rehabilitation, Dhaka Medical College, Dhaka.

4. Dr. Md. Shahadat Hossain, Associate Professor, Department of Physical Medicine \& rehabilitation, Dhaka Medical College, Dhaka.

5. Dr. Md. Jahidul Islam, Assistant Professor, Department of Physical Medicine \& rehabilitation, National Institute of Neurosciences (NINS), Dhaka.

6. Dr. Md. Sohailul Islam, Associate Professor \& Head, Department of Medicine, Nohakhali Medical College, Nohakhali

7. Dr. Durba Halder, Assistant Professor, Department of Medicine, Sir Salimullah Medical College Mitford Hospital, Dhaka

Correspondence: Dr. Md. Ruhul Amin, Registrar, Department of Physical Medicine \& Rehabilitation, Dhaka Medical College, Dhaka. E-mail: www.ruhul_pmr@yahoo.com 
diagnosed as $\mathrm{CP}^{5}$. Spastic cerebral palsy is the most common type, accounting for $75 \%$ of cases which affects a large proportion of this population ${ }^{6}$. Spasticity is one of the common features of cerebral palsy as it contributes to limitations in body structure and function, leading to deformity ${ }^{7}$. Treating the spasticity component of the movement disorder might enable improvement in the performance, participation, and satisfaction in everyday activities of those children ${ }^{6}$. Treatment of spastic cerebral palsy includes physiotherapy along with antispastic medication. Available drugs that are used to treat spasticity include benzodiazepines, baclofen, alpha-adrenergic agonists (tizanidine, clonidine), dantrolene sodium, and gabapentine ${ }^{8}$. Baclofen is a GABA agonist that is used to reduce muscle tone. Intensive rehabilitation may be defined as 1 hourly intervention, 5 days a week, as opposed to a therapy sessions once a week or once every second week ${ }^{9}$. It consists of neurodevelopmental treatment (NDT), therapeutic exercises (TEs) and activities of daily living (ADL) training ${ }^{10}$. The aim of this study was to find out the efficacy of oral baclofen in combination with intensive rehabilitation in reducing spasticity in cerebral palsy.

\section{Methods}

A randomized controlled clinical trial was done in Dhaka Medical College Hospital, Dhaka, between January and December 2011. All the spastic cerebral palsy patients seeking treatment in outpatient department of Physical Medicine $\&$ Rehabilitation and Pediatrics were the reference population. From reference population, patients enrolled in the study who met the inclusion and exclusion criteria. Sample size estimates suggested that 30 subjects in each group would be sufficient to detect a 5\% level of significance. Patients aged between months to 12 years of both sexes; with disorder in the development of movement and posture presumably of cerebral origin started before 2 years of age, presence of spasticity associated with or characterized by increased tone reflexes, clonus or extensor plantar response, and delayed miles stones of development which is improving over time were included in this study. Those with mixed type of cerebral palsy; receiving systemic antispasticity medications or had received phenol and/or botulinum toxin type A injections; past surgical intervention that might interfere with ankle joint movement; neurodegenerative disorders, chromosomal abnormality such as Down syndrome, inborn errors of metabolism such as galactosemia and presence of comorbidity such as epilepsy were excluded.

Procedure: A total number of 60 patients were primarily selected and were randomized into two groups (Group A and Group B), each of which included 30 patients. Complete history and clinical examination were done for all enrolled patients. After taking written informed consent they were finally selected for the study and randomization was done by lottery. In group A only intensive rehabilitation (1 hour daily for 5 days a week for 24 weeks) was given. In group $\mathrm{B}$ intensive rehabilitation (1 hour daily for 5 days a week) and oral baclofen (corresponding to approximately $0.3 \mathrm{mg} / \mathrm{kg}$ a day) in two divided doses was given for 24 weeks. Patients were first assessed with Modified Asworth Scale (MAS) 39 based on muscle tone to determine the extent of spasticity. Then Physician Rating Scale ${ }^{40}$ to measure joint angle (crouch) specially by standard goniometer, ${ }^{46} \mathrm{knee}$ recurvatum, foot contact and overall functional status by Gross Motor Functional Classification System ${ }^{11}$. Then intervention was done by giving oral baclofen with intensive rehabilitation to reduce spasticity in Group B and uniform intensive rehabilitation protocol was applied. After 4 weeks ( $1^{\text {st }}$ follow up) during the continuation of drugs, patients were again assessed by principal investigator using before mentioned 3 scales and adverse effect of oral baclofen was recorded in followup sheet. After 8 weeks ( $2^{\text {nd }}$ follow up) were again assessed by principal investigator using before mentioned 3 scales and adverse effect of oral baclofen was recorded in follow up sheet. Then follow up assessment was done every 4 weekly at $12^{\text {th }}$ week, $16^{\text {th }}$ week, $20^{\text {th }}$ week and lastly $24^{\text {th }}$ week for total with continuing the drugs using same scales by principal investigator. Both groups were given intensive rehabilitation by an experienced physiotherapist at the department of Physical Medicine \& Rehabilitation, Dhaka Medical College Hospital, Dhaka. 
Drug administration and titration: After group allocation, baclofen was given according to following dose schedule. Oral baclofen was started with a very low dose (corresponding to approximately $0.3 \mathrm{mg} / \mathrm{kg}$ a day) in two divided doses.

Intensive rehabilitation: One hour intensive physiotherapy was done daily for 5 days a week. Activities included in each session were body alignment weight transfer in various positions, bimanual activities and facilitation sequences of movements.

Ethical clearance: Ethical clearance has been obtained from the concerned authority to conduct the research work of study subjects.

Data analysis: Data were collected through a pretested structured questionnaire. Data were processed and analyzed using SPSS version 11.0. Test statistics used to analysis the data were chi-square test and student's ' $t$ ' test. The level of significance was set 0.05 and p-value of less than 0.05 was considered significant.

\section{Results}

A total of 60 patients were recruited to yield 38 male and 22 female, $56.7 \%$ male and $43.3 \%$ female in IR group and $70 \%$ male and 30\% female in baclofen + IR group. Mean age (in months) of group A patients was $25.3 \pm 2.8$ and group B was $37.4 \pm 4.9$. In this study, the patients of intensive rehabilitation group were relatively younger compared to Baclofen + IR group ( $p=0.040)$. Though male gender predominant in both groups but sex distribution was not significant ( $\mathrm{p}=0.284)$. Mean weight was considerably higher in Baclofen + IR group compared to intensive rehabilitation group $(\mathrm{p}=0.147)$.

\section{Table I}

Comparison of age sex, weight between two groups

\begin{tabular}{|c|c|c|c|}
\hline \multirow{2}{*}{$\begin{array}{l}\text { Demographic } \\
\text { characteristics }\end{array}$} & \multicolumn{2}{|c|}{ Group } & \multirow{2}{*}{$\begin{array}{c}\mathrm{p}^{-} \\
\text {value }\end{array}$} \\
\hline & $\begin{array}{c}\text { Intensive } \\
\text { rehabilitation } \\
(\mathrm{n}=30)\end{array}$ & $\begin{array}{c}\text { Baclofen } \\
\quad+\text { IR } \\
(\mathrm{n}=30)\end{array}$ & \\
\hline Age (months) \# & $25.3 \pm 2.8$ & $37.4 \pm 4.9$ & 0.04 \\
\hline \multicolumn{4}{|l|}{$\mathrm{Sex}^{*}$} \\
\hline Male & 17 (56.7) & $21(70.0)$ & 0.28 \\
\hline Female & $13(43.3)$ & $9(30.0)$ & \\
\hline Weight (kg) ${ }^{\#}$ & $9.3 \pm 2.7$ & $13.0 \pm 2.5$ & 0.14 \\
\hline
\end{tabular}

Figures in the parenthesis denote corresponding \%;

* 2 Test was employed to analyze the data.

\# Data were analysed using Student's t-Test and were presented as mean $\pm \mathrm{SD}$.
Baseline characteristics shows that Modified Ashworth Scale (MAS) grade was almost identical between intensive rehabilitation and Baclofen + IR groups $(p=0.249)$. The physician rating scale in terms of knee recurvatum, angle for crouch gait and foot contact were almost identical between the two groups $(\mathrm{p}=0.601, \mathrm{p}=0.141$ and $\mathrm{p}=0.600)$. However, the gross motor function was significantly worse in the Baclofen + IR group than that in the intensive rehabilitation group $(p=0.036$ respectively).

\section{Table II}

Comparison of baseline (pretreatment) characteristics between two groups

\begin{tabular}{|c|c|c|c|}
\hline \multirow{2}{*}{$\begin{array}{l}\text { Baseline } \\
\text { characteristics }\end{array}$} & \multicolumn{2}{|c|}{ Group } & \multirow[t]{2}{*}{ p-value } \\
\hline & $\begin{array}{c}\text { Intensive } \\
\text { rehabilitation } \\
(\mathrm{n}=30)\end{array}$ & $\begin{array}{c}\text { Baclofen } \\
+ \text { IR } \\
(\mathrm{n}=30) \\
\end{array}$ & \\
\hline \multicolumn{4}{|c|}{ Modified Ashworth scale score* } \\
\hline 3 & $5(16.7)$ & $4(13.3)$ & \\
\hline 4 & $22(73.3)$ & $18(60.0)$ & 0.24 \\
\hline 5 & $3(10.0)$ & $8(26.7)$ & \\
\hline \multicolumn{4}{|c|}{ Physical rating scale } \\
\hline Knee*Recurvatum & $m>52(6.7)$ & $1(3.3)$ & \\
\hline Recurvatum $<0-5$ & $5 \quad 2(6.7)$ & $4(13.3)$ & 0.60 \\
\hline No Recurvatum & $26(86.7)$ & $25(83.3)$ & \\
\hline \multicolumn{4}{|c|}{ Angle for crouch gait } \\
\hline *Severe & $10(37.0)$ & $6(24.0)$ & \\
\hline Moderate & $16(59.3)$ & $13(52.0)$ & 0.14 \\
\hline Mild & $\mathrm{O}(0.07)$ & $6(24.0)$ & \\
\hline None & $1(3.7)$ & $0(0.0)$ & \\
\hline \multicolumn{4}{|l|}{ Foot contact* } \\
\hline Toe & $25(83.3)$ & $24(80.0)$ & \\
\hline Toe-heel & $5(16.7)$ & $5(16.7)$ & 0.60 \\
\hline Flat & 00 & $1(3.3)$ & \\
\hline \multicolumn{4}{|c|}{ Gross motor function* } \\
\hline Level 2 & - & $1(3.3)$ & 0.03 \\
\hline Level 4 & $11(36.7)$ & $3(10.0)$ & \\
\hline Level 5 & $19(63.3)$ & $26(86.7)$ & \\
\hline
\end{tabular}

Figures in the parenthesis denote corresponding \%; *2 Test was employed to analyse the data.

Outcome of children at month 1 shows that MAS grade 4 and 5 were significantly higher in intensive rehabilitation (group A) than those in the Baclofen + IR (group B). About 7\% 
of children in intensive rehabilitation group had $>5$ degree recurvatum deformity in the knee, and another $7 \%<0-5$ degree compared to $16.7 \%$ and $0 \%$ in Baclofen + IR group respectively. Over one-third (37\%) of children had severe and $63 \%$ moderate flexion angle for crouch gait in group A, while $52 \%$ of children had moderate and $48 \%$ mild crouch gait in group B $(\mathrm{p}<0.001)$. Over three-quarters $(76.7 \%)$ of children in the group A had foot contact with their toes, while $73.3 \%$ in group B had toe-heel foot contact. A higher proportion of children in the latter group exhibited level 5 gross motor function compared to the former group $(p=0.079)$. Outcome of children at month 2, MAS Grade was observed to be reduced in the group $B$ than that in the group A with $13.3 \%$ in the former group having score $0-1$ as opposed to none in the latter group ( $<<0.001)$. Knee recurvatum, angle for crouch gait, foot contact and gross motor function were significantly different between group $A$ and group $B(p<0.001$, $\mathrm{p}<0.001, \mathrm{p}<0.001$ and $\mathrm{p}=0.038$ respectively). Evaluation of outcome at month 3 showed that the MAS Grade was further reduced in group B with $70 \%$ having score $0-1$ as opposed to only $3.3 \%$ in the group A $(\mathrm{p}<0.001)$. The physician rating scale like knee recurvatum, angle for crouch gait, foot contact and gross motor function also responded well in the group $B$ group than those in the group $\mathrm{A}(\mathrm{p}=0.028, \mathrm{p}<0.001$, $p<0.001$ and $p=0.007$ respectively. At 4 months of intervention MAS Grade was further reduced in the group B, while the group A did not respond further $(p<0.001)$. Majority of children in group A $(85.2 \%)$ had moderate and in group $\mathrm{B}(84.6 \%)$ had mild flexion angle for crouch gait $(\mathrm{p}<0.001)$. Over three-quarters $(76.7 \%)$ of children in group A had level 4 and $20 \%$ level 5 gross motor function which in group $\mathrm{B}$ were $36.7 \%$ and $60 \%$ respectively ( $\mathrm{p}=0.007$ ) Outcome of children at month 5 , majority (86.7\%) of children in group B exhibited MAS Grade 0-1 compared $6.7 \%$ in group $A(p<0.001)$. There was no significant difference between the groups in knee recurvatum $(p=0.70)$. Mild angle for crouch gait was significantly higher in group B compared to $7.7 \%$ in group A $(84.6 \%$ vs. $25.9 \%$, $\mathrm{p}<0.001)$. Flat foot was much higher in the group $\mathrm{B}$ than that in the group A $(\mathrm{p}<0.001)$. Gross motor function was significantly heterogeneous between groups $(p<0.001$ and $\mathrm{p}=0.003$ respectively). At 6 months, $76.7 \%$ of children in the group B showed MAS Grade 0-1 compared to $3.3 \%$ in the group A ( $p<0.001)$. Most of the children in both groups had no recurvatum of knee $(p=0.389)$. The incidence of mild angle for crouch gait, flat foot and gross motor function were significantly higher in group $\mathrm{B}$ than those in the group $\mathrm{A}(\mathrm{p}<0.001$, $\mathrm{p}<0.001$ and $\mathrm{p}=0.001$ respectively) (Table-III).

Table III

Comparison of outcome of children at month 6 between groups

\begin{tabular}{|c|c|c|c|}
\hline \multicolumn{3}{|c|}{ Outcome of children } & \multirow{2}{*}{$\begin{array}{c}\text { p- } \\
\text { value }\end{array}$} \\
\hline at month 6 & $\begin{array}{l}\text { Intensive } \\
\text { ehabilitation } \\
(\mathrm{n}=30)\end{array}$ & $\begin{array}{c}\text { Baclofen } \\
+ \text { IR } \\
(\mathrm{n}=30)\end{array}$ & \\
\hline \multicolumn{4}{|c|}{ Modified Ashworth scale Grade* } \\
\hline $0-1$ & $1(3.3)$ & $23(76.7)$ & \\
\hline $2-3$ & $28(93.3)$ & $6(20.0)$ & $<0.001$ \\
\hline $4-5$ & $1(3.3)$ & $1(3.3)$ & \\
\hline \multicolumn{4}{|c|}{ Physician rating scale* } \\
\hline Knee & & & 1.0 \\
\hline Recurvatum $<0-5$ & $3(10.0)$ & $4(13.3)$ & \\
\hline No Recurvatum & 27(90.0) & $26(86.7)$ & \\
\hline \multicolumn{4}{|c|}{ Angle for crouch gait* } \\
\hline Moderate & $20(74.1)$ & $1(4.0)$ & \\
\hline Mild & $7(25.9)$ & $22(88.0)$ & $<0.001$ \\
\hline None & 00 & $2(8.0)$ & \\
\hline \multicolumn{4}{|l|}{ Foot contact* } \\
\hline Toe-heel & $19(63.3)$ & $4(13.3)$ & \\
\hline Flat & $11(36.7)$ & $24(80.0)$ & $<0.001$ \\
\hline Occasional heel-t & toe 00 & $2(6.7)$ & \\
\hline \multicolumn{4}{|c|}{ Gross motor function* } \\
\hline Level 1 & 00 & $1(3.3)$ & \\
\hline Level 2 & 00 & $1(3.3)$ & 0.010 \\
\hline Level 3 & $4(13.3)$ & $0(0.0)$ & \\
\hline Level 4 & $22(73.3)$ & $14(46.7)$ & \\
\hline Level 5 & $4(13.3)$ & $14(46.7)$ & \\
\hline
\end{tabular}

Figures in the parenthesis denote corresponding \%; *2 Test was employed to analyse the data.

In the intensive rehabilitation group, majority of children changed their Asworth Scale Score from $4-5$ at baseline to $2-3$ at month 6 , while in the baclofen + IR group majority changed their score from $4-5$ at baseline to $0-1$ at month 6 . Although both group experienced a 
significant change from their baseline status, the change was more pronounced in the baclofen + IR group $(p<0.001)$ than that in the intensive rehabilitation group $(p=0.007)$.

Most of the children in intensive rehabilitation group with level 5 and 4 gross motor function at baseline changed to level 4 and 3 respectively $(p=0.009)$. Likewise a substantial proportion of children in baclofen + IR group changed from level 5 gross motor function to level 4 and a few to 3 and $2(p<0.001)$.

\section{Discussion}

In this study, 60 children with cerebral palsy were divided into two groups (30 IR and another 30 baclofen+IR group). At the baseline evaluation baclofen+IR group; 4(13.3\%) were Modified Asworth Scale grade 3, 18(60.0\%) grade $4,8(26.7 \%)$ grade 5 . After 6 months, spasticity was significantly reduced; 23(76.7\%) children showed Modified Asworth Scale grade 0-1, $6(20.0 \%)$ were grade $2-3$ and $1(3.3 \%)$ grade $4-5$. In IR group; $5(16.7 \%)$ were Modified Asworth Scale grade 3, 22(73.3\%) grade 4, 3(10.0\%) grade 5. After 6 months, spasticity also significantly reduced in this group; $1(3.3 \%)$ children showed Modified Asworth Scale grade 0-1, 28(93.3\%) were grade $2-3$ and $1(3.3 \%)$ grade $4-5$. In this study we found that baclofen+IR group should better response in reducing spasticity compared to in the IR group ( $\mathrm{p}<0.001)$. Regarding Physician ratings scale, most of the severe and moderate angle for crouch gait at baseline in IR group changed to moderate and mild angle respectively $(\mathrm{p}=0.019)$. However the baclofen+IR group experienced more improvement, with most of the severe and moderate angle for crouch gait at baseline changed to mild a few to none $(p<0.001)$. Changes in knee recurvatum in both groups were not significant as very few children had knee recurvatum $>5$ or $<0-5(p=0.688)$. During measuring crouch, the patient in the IR group had at baseline 37\% severe and 59\% moderate angle at baseline and at $1^{\text {st }}$ month scores were found no change. But baclofen+IR baseline scores were $24 \%$ and $52 \%$ respectively and at $1^{\text {st }}$ month scores were $0 \%$ and $52 \%$. IR group $(p=0.007)$ also show improvement in angle for crouch but baclofen+IR group $(\mathrm{p}<0.001)$ change more significantly. In this study most of the children having foot contact with their toes at baseline in IR group changed to toe-heel contact $(63.3 \%)$ or flat foot $(36.7 \%)(p=0.029)$. The children of the baclofen+IR group also demonstrated a similar change $180 \%$ of the children at baseline had foot contact with their toes, but at 6 months of evaluation $80 \%$ showing flat foot). The change was more noted in the baclofen+IR group $(\mathrm{p}<0.001)$. In gross motor function level, most of the children in IR group with level 5 and 4 gross motor function at baseline changed to level 4 and 3 respectively $(p=0.009)$. Likewise a substantial proportion of children in the baclofen+IR group changed from level 5 gross motor function to level 4 and a few to level 3 and level $2(\mathrm{p}<0.001)$ which indicate better improvement in activities in daily life in baclofen+IR group. In a study Intermittent versus continuous physiotherapy in children with cerebral palsyChristiansen et al. ${ }^{14}$ reported that GMFM-66 score increased significantly in both intermittent and continuous group. Baclofen has been poorly studied in spasticity of cerebral origin with most studies evaluating efficacy in treating spasticity of spinal cord origin. Although no studies on the use of baclofen to treat children was found, it is still commonly recommended as a treatment option for children with spasticity ${ }^{15,16}$. Baclofen is stable in liquid form, but can only be given enterally (except if given intrathecally). Baclofen cannot be given intravenously and is not absorbed rectally ${ }^{17}$. Children can have similar withdrawal symptoms as in adults, which includes hallucinations and seizure ${ }^{18}$. The usually starting dose is $2.5 \mathrm{mg}$ a day and titrated up every 3-5 days to a maximum of $20-60 \mathrm{mg}$. per day ${ }^{19}$. In a study of infants receiving physical therapy, Scherzer et al noted improvement in broadly defined motor and social skills and in the patient's ability to address the children's daily needs, but could not separate the influences of age, therapy and cognitive level ${ }^{13}$. In the study in Norway to assess the effects of intensive physiotherapy in cerebral palsy. A single-subject design was used. Intervention consisted of two 4-week periods of daily physiotherapy, interrupted by 8 
weeks of physiotherapy as usual. The children were assessed every 4th week using the Gross Motor Function Measure. Results were visually analyzed, and statistical significance of Gross Motor Function Measure-66 scores was established with the 2 SD band method. Compliance was high. All infants showed gross motor progress compared with baseline, but separating effect of daily physiotherapy from physiotherapy as usual was inconclusive. Parents preferred the intensive treatment alternative. Blocks of intensive therapy can be an alternative to regular dosage of physiotherapy, however, until further studies are conducted, the physiotherapy intervention, intensity, and frequency should be tailored to meet the needs of each individual infant and family ${ }^{20}$.

Analytical findings of this study showed that combined baclofen and intensive rehabilitation is more beneficial to decrease stiffness and spasm and thereby improving movement in a young child with cerebral palsy.

\section{Conclusion}

The study showed that basic motor abilities and self-care improved after intensive physiotherapy with baclofen is effective for reducing generalized spasticity regarding muscle tone and joint angle stiffness and gait improvement in cerebral palsy patients over intensive rehabilitation.

\section{References}

1. Rosenbaum P, Paneth N, Leviton A. A report: the definition and classification of cerebral palsy April 2006. Dev Med Child Neurol 2007; 109: 8-14.

2. Thomas MO Diagnosis Treatment and prevention of cerebral palsy. Clin Obstet Gynecol 2008; 514: 816-28

3. Surveillance of Cerebral Palsy in Europe (SCPE). Surveillance of cerebral palsy in Europe: a collaboration of cerebral palsy surveys and registers. Dev Med Child Neurol 2000; 42(12): 816-24.

4. Reddighough DS, Collins KJ.The epidemiology and causes of cerebral palsy. Aust J Physiother 2003; 49(1): 456-62.

5. Khan MSZ. A study on patients with cerebral palsy attending Physical Medicine Department of BSMMU. Bangladesh Med Res Counc Bull 1998; 24: $50-2$.
6. Tal KC, Tal J, Aviva FV. Upper extremity function and occupational performance in children with spastic cerebral palsy following lower extremity botulinum toxin injections. J Child Neurol 2010; 25(6): 694-700.

7. Yam WK, Leung MS. Interrater reliability of Modified Ashworth Scale and Modified Tardieu Scale in children with spastic cerebral palsy. J Child Neurol 2006; 21: 1031-5.

8. Katz RT. Management of spastic hypertonia after stroke. J Neurol Rehabil 1991; 5: s5-s12.

9. Tordis U, Anne BS, Anne EL. Effects of intensive physiotherapy in infants newly diagnosed with cerebral palsy. Pediatr Phys Ther 2009; 21 : 140-9.

10. Rosenbaum P, Dan B, Leviton A, Paneth N, Jacobsson B, Goldstein M. Proposed definition and classification of cerebral palsy. Dev Med Child Neurol 2005; 47: 471-6.

11. Milla PJ, Jackson AD. A controlled trial of baclofen in children with cerebral palsy. J Int Med Res 1977; 5: 398-440.

12. Wright T, Nicholson J. Physiotherapy for the specific child: an evaluation. Dev Med Child Neurol 1973; 15: 146-63.

13. Scherzer AL, Mike V, Llpon J. Physical therapy as a determinant of change in the cerebral palsied infant. Pediatrics 1976; 58: 47-52.

14. Christiansen AS, Lange C. Intermittent versus continuous physiotherapy in children with cerebral palsy. Dev Med Child Neurol, 2008; 50: 290-3.

15. Whyte J, Robinson K. Pharmacologic Management. The practical management of spasticity in children and adults. Philadelphia: Lea and Febiger; 1990: p.209.

16. Stempien L, Gaebler-Spira D. Rehabilitation of children and adults with cerebral palsy. In: Physical Medicine and Rehabilitation. Philadelphia: WB Saunders; 1996: p.1113-32.

17. Kriel R, Krach L, Hoff D, Gormley M, Jones-Saete C. Failure of absorption of after rectal administration. Pediatr Neurol 1997; 16(4): 351-2.

18. Reisman M, et al. Hallucinations association with acute baclofen withdrawal: report of two pediatric cases. Kansas City, MO, USA. 47 th Annual Assembly of the American Academy of Physical Medicine and Rehabilitaiton. 1997.

19. Gracies JPN, Elovic E, McGuire J, Simpson D. Traditional Pharmacological Treatments for Spasticity Part II: General and Regional Treatments. Muscle Nerve 1997; 6: s100.

20. Pellegrino L. Cerebral palsy. In: Batshow ML. ed. Children with disabilities. $4^{\text {th }}$ ed. Baltimore: Paul H. Brookes publishing; p.499-528. 